\title{
A NEW FORM OF SPRAY APPARATUS.
}

\author{
By WILLTAM. ROBERTSON, M.D., D.P.H., \\ Medical Officer of Health, Leith.
}

AT the Congress of the British Institute of Public Health held at Eastbourne during the summer of 1901, I read a paper on the "Disinfection of Rooms" (see Journal of British Institute, May, 1902), and took the opportunity to describe a form of tank that I had devised for the disinfection of interiors.

I had always felt that an apparatus that demanded the employment of both hands to use it could be improved upon, and the tank was the outcome of experiments that I had made.

At the outset, as far away now as the year 1900, an ironmonger secured for me a double action pump, the lower end of which rested in the pail or vessel used for containing the disinfecting solution. A foot-piece steadied the pump, and during my concluding months of official connection with Paisley all rooms were disinfected with this simple apparatus. The spray nozzle was too coarse, however, and complaints began to reach me regarding over wetting of floors and surfaces. This spray was given up, and I again resorted to the use of the Defries machine. I then turned my attention to the tank idea, which I described at Eastbourne, though the double action pump, it should be said, was still used for the spraying of wards, notably those at the small-pox hospital. This pump, with certain modifications and improvements, is now sold by the Thresh Company as Dr. Mackenzie's spray; but the nozzle is a very much better one than that used by me, and its spray is cloudlike and fine.

The tank devised to meet the difficulties of portability and easy working was made of copper, and capable of holding a gallon and a half of fluid. The fluid was first poured into the tank; then, by means of a strong bicycle pump, air was forced in until a sufficiency was stored, the amount being roughly gauged. The tank was next slung round the neck of the disinfecting officer, who screwed on the nozzle and rubber pipe attachment, and proceeded to spray the desired surfaces. This apparatus achieved a double object. First, it was portable, in the sense that the disinfecting officer could move about freely, and was not required to lift pails or other vessels containing the disinfecting solution; and secondly he had both hands free to guide the nozzle. The reserve air in the tank was quite sufficient to maintain a uniform spray for fully ten minutes; but 
the tank was heavy and somewhat cumbrous, and its shape did not add to its power of resisting great air pressure. To overcome the weight difficulty, I experimented with an ordinary Rugby football. This was very convenient, since it could be packed away into small compass when not in use. Again, however, I was confronted with the weakness of the leather covering, which burst so soon as a pressure of 30 pounds to the square inch was reached. My mind then went to other solutions of the spray problem, but, despite repeated trials, I was unable to hit upon anything simpler than either the tank or football. In either case the spray could be kept up for ten minutes, and that without continuous pumping. This feature alone seemed to me to commend the apparatus, since every other form of spraying machine requires almost continuous pumping.

About four months ago there came under my notice a tank that

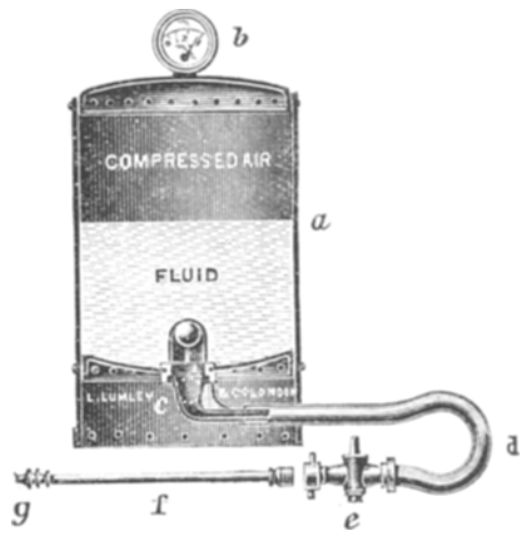

professed to do the very thing that I had been aiming at-namely, the maintenance of a spray for a considerable time. I have now used this tank during the past three months, and, armed with such an experience, I am, I think, justified in describing it as an admirable instrument for the disinfection of houses, ships, vehicles, etc.

The principle of the apparatus is as follows: Into a tank fitted with a pressure gauge is forced air until a pressure of 15 pounds to the square inch is recorded. The same pump is employed, without disconnecting it from the tank, to next force in fluid until the gauge shows a pressure of 45 pounds. I find that after a little over a gallon and a half of disinfecting solution have been forced into the tank, the necessary pressure of 45 pounds is reached. So soon as this part of the work is finished, the tank is slung on the back, 
knapsack fashion, and, the pump having been replaced by the flash tube and nozzle attachment, the disinfecting officer is free to move about at his work. The spray will last for fully twenty minutes without interruption. A stopcock is provided so that the spray may be turned on or off at will.

At the end of twenty minutes the spray comes to a sudden stop, on account of the operation of a ball valve inside the tank. So long as there is fluid in the tank the valve floats, but with the escape of the last of the fluid, the valve drops and seals up the outlet tube in the interior of the tank.

There is thus a constant amount of air pressure confined in the tank; and the sole aim of the disinfecting officer comes to be the foreing in of fluid, which he can do with thirty strokes of the pump. A glance at the illustration will greatly simplify my description. The valve is retained in position by a small cage, inside which the ball floats so long as there is fluid in the tank. To recharge or clean out the tank it must be turned upside down, when one or two strokes of the pump will push aside the valve to permit the escape of the imprisoned air.

After I had tried the original tank on repeated occasions several improvements suggested themselves to me, and these the makers of the apparatus have embodied. The sole objection to the tank is its size, which militates against its being carried about for long distances. But, on the other hand, one must consider that if one knows how many rooms are to be dealt with, one can place the charged tank in a van and go from house to house without replenishing the original stock of fluid and air.

The tank at present in use in Leith can always be relied upon to complete the spraying of three or four rooms. On one occasion three rooms and a staircase were sprayed, and there yet remained a reserve sufficient to half complete a fourth apartment in another house. The disinfecting officer soon becomes expert at his work, and he will find that with this tank he can easily deal with an ordinary-sized room in five minutes.

I asked the makers to construet for me a smaller tank in order to get over the transport difficulty, and while the tank made is much lighter, its size only permits of the storing of fluid and air to maintain a spray for ten minutes. As the larger tank keeps spraying for twenty minutes, I think that feature more than compensates for the additional weight. The small tank I now use at the isolation hospital for spraying the interiors of the ambulaneewaggons.

The bigger tank, which is recommended, appears at first sight 
to be heavy, but when slung on the back its weight is so evenly distributed by a curved surface adapting itself to the bends of the body that no inconvenience is felt by the person carrying the apparatus. To resist the great pressure of 45 pounds the parts must be strong, but their strength is a saving in the long-run, since repairs will scarcely be necessary. The nozzle is of a peculiar construction, and, as it can be turned up or down with a touch of the finger, the spray may be directed under beds and into awkward corners.

Instead of carrying the tank on the back, a specially long rubber tube may be provided, so that the tank can be set in the middle of the floor, and disinfection of surfaces proceeded with.

I have tested the spray very severely. At the isolation hospital I sprayed an annexe where there were many odd corners and partitions, and was able to go over the whole of the surfaces very comfortably within five minutes; the cubic capacity of the apartment was over 1,500 feet. The fact that the spray is constant and diffuse makes it imperative that one must not tarry by the way; one is impelled to move briskly from one part of the room to another.

Quite recently a narrow and dark forecastle required disinfection after the occurrence of small-pox. Spraying machines that called for pumping would have been extremely unwieldy in such a place, yet, with the tank on his back, the disinfecting officer was able to go twice over the surfaces of the forecastle interior quite comfortably, and when finished with this part of the steamer be went aft and sprayed several cabins.

Armed with sueh a tank school janitors could periodically disinfect class-rooms. The apparatus is very simple to understand and to work, and one can step upon tables, chairs, etc., to reach any surface desired.

Knowing what we do about the spread of phthisis through the ageney of dried sputa, the systematic disinfection of schools, public halls, free libraries, etc., with such a spray would not only be easy, but of immense value.

Should one have charge of an isolation hospital I would advise the purchase of two flash tubes, one for use in houses, the other, about 6 feet long, to disinfect the walls and ceilings of wards. This apparatus is made by L. Lumley and Co., Ltd., 1, America Square, Minories, London, and its price is $£ 33 \mathrm{~s}$. I think it very necessary to point out that I have no pecuniary interest in the tank or in the firm in question. There might be the suggestion to the contrary, owing to my strong advocacy of the spraying machine. 